International journal on applications of graph theory in wireless ad hoc networks and sensor networks

(GRAPH-HOC) Vol.3, No.4, December 2011

\title{
Radio Number Of Wheel Like Graphs
}

\author{
A. A. Bhatti*, Aster Nisar*, Maria Kanwal* \\ National University Of Computer And Emerging Sciences,Lahore, Pakistan \\ E-Mail: Akhlaq.Ahmad @ Nu.Edu.Pk, Asternisar @ Gmail.Com, \\ Mariakanwal @ Gmail.Com
}

\begin{abstract}
.
In this paper we establish the radio number for Flower Wheel graph $\left(F W_{n}^{k}\right), k$-Wheel graph $(k W)$ and Joint-Wheel graph $\left(W H_{n}\right)$.

AMS Subject classification: $05 C 78$ (05C15)
\end{abstract}

\section{Keywords:}

Radio number, Radio labeling, Flower Wheel graph $\left(F W_{n}^{k}\right), k$-Wheel graph $(k W)$, Joint-Wheel graph $\left(W H_{n}\right)$

\section{INTRODUCTION}

A radio labeling is an assignment of labels, traditionally represented byintegers, to the vertices of a graph. Formally, for a given graph $\mathrm{G}=(\mathrm{V}, \mathrm{E})$ with $\mathrm{V}$ being the set of vertices and $\mathrm{E}$ being the set of edges, a radio label-ing is a function from the vertices of the graph to some subset of positiveintegers.

For a set of given stations, the task is to assign to each city a channel, which is a non-negative integer, so that interference is prohibited and the span of the channel assigned is minimized. Hale was the first who proposed graph to model these channel assignment in 1980 [5]. Later in 2001

Chartrand, Erwin, Zhang, and Harary were motivated by regulations for channel assignments of FM radio stations to introduce the radio labeling of graphs [1]. Usually, the level of interference between any two stations is closely related to the geographic locations of the station, the closer are the stations the stronger is the interference. Suppose we consider two levels of interference, major and minor. Major interference occurs between two very close stations; to avoid it, the channel assigned to a pair of very close 
International journal on applications of graph theory in wireless ad hoc networks and sensor networks

(GRAPH-HOC) Vol.3, No.4, December 2011

*The research work is partially supported by National University of Computer and EmergingSciences(NUCES-FAST), Lahore, Pakistan .

stations have to be at least two apart. Manor interference occurs between close stations; to avoid it, the channel assigned to a pair of close stations should be different. To model this problem, we construct a graph $\mathrm{G}$ byrepresenting each station by a vertex and connecting two vertices by an edge if the geographical locations of the corresponding stations are very close. Two close stations are represented by, in the corresponding graph $\mathrm{G}$, a pair of vertices that are distance two apart.

For a simple graph $\mathrm{G}$, let diam ( $\mathrm{G}$ ) denote the diameter of $\mathrm{G}$ which is themaximum shortest distance between two distinct vertices. For any two vertices $u$ and $v$ in $G$, let $d(u, v)$ denote the smallest distance between $u$ and $v$. Radio labeling(multi-level distance labeling or distance labeling) for $\mathrm{G}$ isa one-to-one mapping $\mathrm{f}: \mathrm{V}(\mathrm{G}) \rightarrow \mathrm{Z}+$ satisfying the condition

$$
d(u, v)+|f(u)-f(v)| \geq 1+\operatorname{diam}(G)
$$

for all $u, v \in V(G)$. The span of a labeling $\mathrm{f}$ is the maximum integer thatf maps to a vertex of a graph $\mathrm{G}$. The radio number $(r n(G))$ of $\mathrm{G}$ is thelowest span over all radio labelings of the graph. We will refer to inequality(1.1) as the radio condition. Note that this condition necessitates the useof distance integers, thus $r n(G) \geq|V(G)|$ for all graphs $G$. Radio labelingare sometimes referred to as multi-distance labeling and they are equivalentto $\mathrm{k}$-labeling for $k=\operatorname{diam}(\mathrm{G})$. In this paper we will consider simple andundirected graph.

\section{Some Known Results}

In this section we recall some known results about the radio number ofgraphs. Chartrand, Erwin, and Zhang [1] gave the upper bound for theradio number of Path $\left(P_{n}\right)$.

Theorem 2.1.[1] For any positive integer n,

$$
r n\left(P_{n}\right) \leq \begin{cases}2 k^{2}+k, & \text { if } \quad n=2 k+1 \\ 2\left(k^{2}-k\right)+1, & \text { if } \quad n=2 k\end{cases}
$$

where $P_{n}$ is the Path on $\mathrm{n}$ vertices. Moreover, the bound is sharp when $2 \leq n \leq 5$.

The exact value for the radio number of Path was given by Liu, and Zhu[8].

Theorem 2.2. [8] For any $n \geq 4$,

$$
r n\left(P_{n}\right)=\left\{\begin{array}{lll}
2 k^{2}+2, & \text { if } & n=2 k+1 \\
2 k(k-1)+1, & \text { if } & n=2 k .
\end{array}\right.
$$

Also, Liu and Zhu [8] gave the radio number for $\operatorname{Cycle}\left(C_{n}\right)$.

Theorem 2.3. [8] Let $_{n}$ be an $n$-vertex Cycle. For $n \geq 3$ we have 
International journal on applications of graph theory in wireless ad hoc networks and sensor networks (GRAPH-HOC) Vol.3, No.4, December 2011

$$
r n\left(C_{n}\right)=\left\{\begin{array}{lll}
\left(\frac{n-2}{2}\right) \phi(n)+1, & \text { if } & n \cong 0,2(\bmod 4) ; \\
\left(\frac{n-1}{2}\right) \phi(n), & \text { if } & n \cong 1,3(\bmod 4),
\end{array}\right.
$$

where

$$
\phi(n)=\left\{\begin{array}{lll}
k+1, & \text { if } & n=4 k+1 ; \\
k+2, & \text { if } & n=4 k+r
\end{array} \text { for } \quad r=0,2,3 .\right.
$$

However Chartrand, Erwin, Harary, and Zhang [2] obtained different valuesthan Liu and Zhu [8]. They found the lower and upper bound for the radionumber of $\operatorname{Cycle}\left(\mathrm{C}_{\mathrm{n}}\right)$.

Theorem 2.4. [2] For $\mathrm{k} \geq 3$,

$$
r n\left(C_{n}\right) \leq\left\{\begin{array}{lll}
k^{2}, & \text { if } & n=2 k+1 \\
k^{2}-k+1, & \text { if } & n=2 k
\end{array}\right.
$$

and

$$
r n\left(C_{n}\right) \geq 3\left\lceil\frac{n}{2}-1\right\rceil-1, \quad \text { for } \quad n \geq 6 .
$$

Liu [7] gave the lower bound for the radio number of Tree $\left(T_{n}\right)$.

Theorem 2.5.[7]If $\mathrm{T}_{\mathrm{n}}$ isann-vertexrootedtreewithdiameterd.Then

$$
r n\left(T_{n}\right) \geq(n-1)(d+1)+1-2 w\left(T_{n}\right),
$$

wherew $\left(T_{n}\right)$ represent theweight.

TheexactvaluefortheradionumberofHypercube(Qn)wasgivenbyR. KhennoufaandO.Togni[6].

Theorem 2.6.[6]Foranypositiveintegern $\geq 1$,

$$
\operatorname{rn}\left(Q_{n}\right)=\left(2^{n-1}-1\right)\left\lceil\frac{n+3}{2}\right\rceil+1 .
$$

M.M.Rivera,M.Tomova,C.Wyels, andA.Yeager[10] gavetheradio numberofCn_Cn,wheredenotetheCartesianproduct.

Theorem 2.7.[10]Foranynon-negativeintegerk, wehave

$$
r n\left(C_{2 k} \square C_{2 k}\right)=2 k^{3}+4 k^{2}-k
$$

and

$$
r n\left(C_{2 k+1} \square C_{2 k+1}\right)=2 k^{3}+4 k^{2}+2 k-1 .
$$


International journal on applications of graph theory in wireless ad hoc networks and sensor networks

(GRAPH-HOC) Vol.3, No.4, December 2011

In[3] C.Fernandez, A.Flores, M.Tomova, and C.Wyelsworkedon find- ingt he radionumber for Completegraph, Stargraph, Complete Bipartite graph, Wheelgraph and Geargraph. They have proved the following results:

$$
\begin{array}{ll}
\cdot r n\left(K_{n}\right)=n . & \\
\cdot r n\left(S_{n}\right)=n+2 . & \\
\cdot r n\left(K_{m, n}\right)=m+n+1 . & \text { for } n \geq 5 . \\
\cdot r n\left(W_{n}\right)=n+2 & \text { for } n \geq 4 . \\
\cdot \operatorname{rn}\left(G_{n}\right)=4 n+2 &
\end{array}
$$

M.T.RahimandI.Tomescu[9]investigatedtheradionumberofHelm $\operatorname{graph}\left(\mathrm{H}_{\mathbf{n}}\right)$.Theyprovedthefollowingresult.

Theorem 2.8. [9]LetHnbeaHelmgraph.Forn $\geq 5$ wehave

$$
r n\left(H_{n}\right)=4 n+2 \text {, }
$$

wherendenotesthenumberofverticesinacycle.

\section{New Result}

The radio number ofFlower Wheel graph $\left(\mathrm{FW}^{\mathrm{k}}\right)$ : Inthissection wewillfind

The radionumber of Flower Wheelgraph $\left(\mathrm{FW}^{\mathrm{K}}\right)$. ${ }_{n}$ First of all we will find the lowerbound by examining labels which have minimum distance between them. For an upperbound, we find a specific radiolabeling which gives us span equal to the lowerbound. FlowerWheelgraph consist of kdisjoint copies of Wheelgraph $\left(\mathrm{W}_{\mathbf{n}}\right)$ meeting in a commonvertex (differentfromhub). The commonvertex of all the copies of Wheel is named as the centralvertex. Its clearthat $\mathrm{FW}^{\mathrm{k}}$ has $(\mathrm{t}+3) \mathrm{k}+1$ verticesanddiam $\left(\mathrm{FW}^{\mathrm{k}}\right)=4$ forall $\mathrm{n} \geq 5$, where $\mathrm{n}$ is the number of vertices in onecopy of Wheelgraph. We denote the number of vertices (in one copyofwheel)which a renonadjacent to the central vertex by $t$. We consider the case when all the copies of Wheelgraph have same number of vertices.

ThelabelingofFW ${ }^{\mathrm{k}}$ isdefinedasfollows:

Toestablishtheradio numberofFW ${ }^{\mathrm{k}}$ wewillrefertoalabelingofthevertices $\{\mathrm{z}, \mathrm{v} 1, \mathrm{v} 2, \ldots, \mathrm{v} 2 \mathrm{k}$,

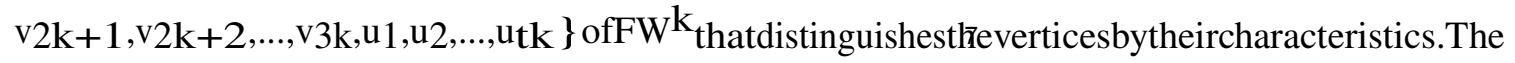
centralvertexislabeledasz, theverticesadjacenttozarelabeledsequentiallyby $\{\mathrm{v} 1, \mathrm{v} 2, \ldots, \mathrm{v} 2 \mathrm{k}, \mathrm{v} 2 \mathrm{k}+1$, $\mathrm{v} 2 \mathrm{k}+2, \ldots, \mathrm{v} 3 \mathrm{k}\}$ in clockwise direction. From Figure 2 it is clear that firstly we label $\{\mathrm{v} 1, \mathrm{v} 2$, $\left.\ldots, v_{2} \mathrm{k}\right\}$ where $\mathrm{v}_{1}$ is not the hub ver- tex, and after labeling these verticeswe label $\{\mathrm{v} 2 \mathrm{k}+1$, $\mathrm{v} 2 \mathrm{k}+2, \ldots, \mathrm{v} 3 \mathrm{k}\}$ (whichare actually the hub vertices). Vertices which are not adjacent to $\mathrm{z}$ are labeled sequentially by $\left\{\mathrm{u}_{1}, \mathrm{u}_{2}, \ldots, \mathrm{utk}\right\}$ in clockwise direction. We specifyu 1 adjacentto v1 and $\mathrm{v} 2 \mathrm{k}+1$. The labeling of $\mathrm{FW}^{4}$ is shown in Figure 2. 
International journal on applications of graph theory in wireless ad hoc networks and sensor networks

(GRAPH-HOC) Vol.3, No.4, December 2011

First of all we will find the radio number of $\mathrm{FW}^{\mathrm{k}}$. Its a special case of $\mathrm{FW}^{\mathrm{k}}{ }_{4}$ whent $=0$, where $\mathrm{t}$ is number of vertices(in one copy) which are non-adjacent to $\mathrm{z}$. We can follow the above procedure to label the vertices of $\mathrm{FW}^{\mathrm{k}}$.

Theorem 3.1. For $\mathrm{k} \geq 2, \operatorname{rn}\left(\mathrm{FW}_{4}^{\mathrm{k}}\right)=3 \mathrm{k}+2$.

Proof.First of all we will find the lower bound for the radio number ofFWk ${ }^{\mathrm{k}} \quad 4$

Lowerbound for $\operatorname{rn}\left(\mathrm{FW}_{4}\right)$ : Assume $\mathrm{k} \geq 2$. Since $\operatorname{diam}\left(\mathrm{F}_{4} \mathrm{~W}^{\mathrm{k}}\right)=2$, soany radio labeling fof $\mathrm{FW}_{4} \mathrm{k}_{\text {must satisfy the radio condition i.e. }}$

$\mathrm{d}(\mathrm{u}, \mathrm{v})+|\mathbf{f}(\mathrm{u})-\mathbf{f}(\mathrm{v})| \geq 1+\operatorname{diam}\left(\mathrm{F} \mathrm{W}_{n}^{\mathrm{k}}\right) \geq 3$

hold for all distinct $\mathrm{u}, \mathrm{v} \in \mathrm{V}\left(\mathrm{FW}_{4}{ }_{4}\right)$. To determine the lower bound wehave to count theminimum number of restricted values associated with the vertices of $\mathrm{FW}^{\mathrm{k}}{ }_{4}$ Let $\mathbf{f}(\mathrm{z})=\mathrm{a}$, where a $\in \mathrm{Z}^{+}$. Since $\mathrm{d}(\mathrm{z}, \mathrm{v} \mathbf{i})=1$, where $\mathrm{z}=\mathrm{v} \mathbf{i}$ for $1 \leq \mathbf{i} \leq 3 \mathrm{k}$. The radio condition becomes

$\mathrm{d}(\mathrm{z}, \mathrm{v} \mathbf{i})+|\mathbf{f}(\mathrm{z})-\mathbf{f}(\mathrm{v} \mathbf{i})| \geq 1+\operatorname{diam}\left(\mathrm{FW}_{4}^{\mathrm{k}}\right)$, or $1+|\mathbf{f}(\mathrm{z})-\mathbf{f}(\mathrm{v} \mathbf{i})| \geq 3$, or $\quad|\mathbf{f}(\mathrm{z})-\mathbf{f}(\mathrm{v} \mathbf{i})| \geq$ 2. So, there existone restricted value associated withz. If $\mathrm{d}(\mathrm{v} \mathbf{i}, \mathrm{v} \mathbf{j}) \leq 2$, where $1 \leq \mathrm{i}, \mathbf{j} \leq 3 \mathrm{k}$, then the radio condition becomes

$\mathrm{d}\left(\mathrm{v}_{\mathbf{i}}, \mathrm{v}_{\mathbf{j}}\right)+\left|\mathbf{f}\left(\mathrm{v}_{\mathbf{i}}\right)-\mathbf{f}\left(\mathrm{v}_{\mathbf{j}}\right)\right| \geq 1+\operatorname{diam}\left(\mathrm{F} \mathrm{W} \mathrm{W}^{\mathrm{k}}\right)$, or $2+\left|\mathbf{f}\left(\mathrm{v}_{\mathbf{i}}\right)-\mathbf{f}\left(\mathrm{v}_{\mathbf{j}}\right)\right| \geq 3$,or $\left|\mathbf{f}\left(\mathrm{v}_{\mathbf{i}}\right)-\mathbf{f}\left(\mathrm{v}_{\mathbf{j}}\right)\right| \geq 1$. So, we can assign the consecutive integers to the following sets $\left\{\mathrm{v}_{1}, \mathrm{v}_{3}, \ldots, \mathrm{v} 2 \mathrm{k}-1\right\},\{\mathrm{v} 2, \mathrm{v} 4, \ldots$, $\mathrm{v} 2 \mathrm{k}\}$ and $\{\mathrm{v} 2 \mathrm{k}+1, \mathrm{v} 2 \mathrm{k}+2, \ldots, \mathrm{v} 3 \mathrm{k}\}$ respectively. Therefor, there exist no restricted value associated with $v \mathbf{i}$ for $1 \leq \mathbf{i} \leq 3 \mathrm{k}$. Hence, there is only one restricted value associated with any label of $_{4}$ $\mathrm{FW}^{\mathrm{k}}$. Thus, $\pi n\left(F W^{k}\right) \geq$ allowed values+restricted value

Hence, $r n\left(F W_{4}^{k}\right) \geq 3 k+1+1=3 k+2$.

Upper bound for $r n\left(F W_{4}^{k}\right)$ :If $\mathbf{f}$ is any radio labeling of $\mathrm{FW}_{4}^{\mathrm{k}}$ then ${ }^{\text {span }}$ of this labeling will provide an upper bound for the radio numberof $F W^{\mathrm{k}}$. In order to find an upper bound we define a radio labeling $\mathbf{f}: \mathrm{V}_{4}\left(\mathrm{~F} \mathrm{~W}^{\mathrm{k}}\right) \rightarrow \mathrm{Z}^{+}$as follows: 
International journal on applications of graph theory in wireless ad hoc networks and sensor networks (GRAPH-HOC) Vol.3, No.4, December 2011

$\mathbf{f}(\mathrm{z})=1$,

$\mathbf{f}(\mathrm{v} 2 \mathbf{i}-1)=2+\mathbf{i}, \quad$ for $\quad 1 \leq \mathbf{i} \leq \mathrm{k}$,

$\mathbf{f}(\mathrm{v} 2 \mathbf{i})=2+\mathrm{k}+\mathbf{i}, \quad$ for $\quad 1 \leq \mathbf{i} \leq \mathrm{k}$,

$\mathbf{f}(\mathrm{v} 2 \mathrm{k}+\mathbf{i})=2(1+\mathrm{k})+$ for $\quad 1 \leq \mathbf{i} \leq \mathrm{k}$.
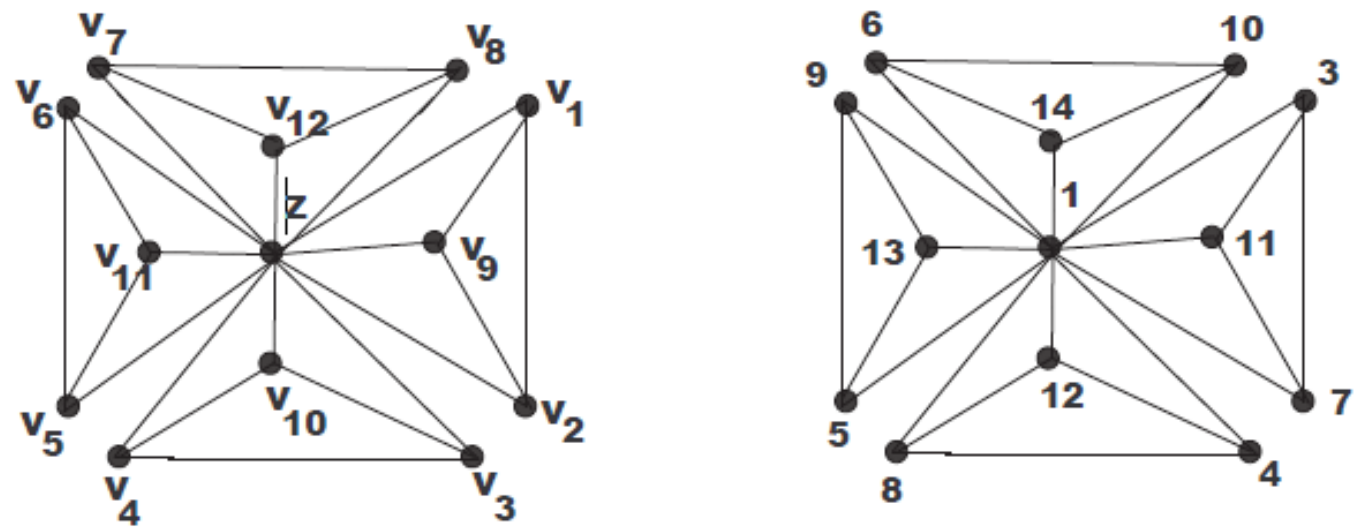

Figure 1. Radio labeling of $\mathrm{FW}_{4}^{4}$

Claim:The labeling $\mathbf{f}$ is a valid radio labeling. Wehave to show that the radio condition

$d(u, v)+|\boldsymbol{f}(u)-\boldsymbol{f}(v)| \geq 1+\operatorname{diam}\left(F W_{4}^{k}\right) \geq 3$

holds for all distinct $u, v \in V\left(F W_{4}^{k}\right)$. We will discuss twocases:

Case1:Since $\mathrm{d}\left(z, v_{\boldsymbol{i}}\right)=1$, where $1 \leq \boldsymbol{i} \leq 3 k$ and $\boldsymbol{f}(z)=1, \boldsymbol{f}\left(v_{\boldsymbol{i}}\right) \geq 3$. The radio condition in this case will be

$d\left(z, v_{\boldsymbol{i}}\right)+\left|\boldsymbol{f}(z)-\boldsymbol{f}\left(v_{\boldsymbol{i}}\right)\right| \geq 1+|1-3|$, or $d\left(z, v_{\boldsymbol{i}}\right)+\left|\boldsymbol{f}(z)-\boldsymbol{f}\left(v_{\boldsymbol{i}}\right)\right| \geq 3$.

Hence, the radio condition is satisfied.

Case2:Since $d\left(v_{\boldsymbol{i}}, v_{\boldsymbol{j}}\right) \leq 2$, where $1 \leq i, \boldsymbol{j} \leq 3 k$ and $\boldsymbol{f}\left(v_{\boldsymbol{i}}\right) \geq 3$. The possible label difference for each pair will satisfy $\left|\boldsymbol{f}\left(v_{\boldsymbol{i}}\right)-\boldsymbol{f}\left(v_{\boldsymbol{j}}\right)\right| \geq 1$. Theradio condition in this case will be

$$
d\left(v_{\boldsymbol{i}}, v_{\boldsymbol{j}}\right)+\left|\boldsymbol{f}\left(v_{\boldsymbol{i}}\right)-\boldsymbol{f}\left(v_{\boldsymbol{j}}\right)\right| \geq 2+1, \text { or } d\left(v_{\boldsymbol{i}}, v_{\boldsymbol{j}}\right)+\left|\boldsymbol{f}\left(v_{\boldsymbol{i}}\right)-\boldsymbol{f}\left(v_{\boldsymbol{j}}\right)\right| \geq 3 .
$$

Hence, the radio condition is satisfied.

These twocases establish the claim that $\mathbf{f}$ is a valid radio labeling of $\mathrm{FW}_{4}^{\mathrm{k}}$.

Thus, $r n\left(\mathrm{FW}_{4}^{\mathrm{k}}\right) \leq \operatorname{span}(\mathbf{f})=3 \mathrm{k}+2$.

From the lower and upper bound of $\operatorname{rn}\left(\mathrm{FW}_{4}^{\mathrm{k}}\right)$, we have

$\operatorname{rn}\left(\mathrm{FW}_{4}^{\mathrm{k}}\right)=3 \mathrm{k}+2$. 
International journal on applications of graph theory in wireless ad hoc networks and sensor networks

(GRAPH-HOC) Vol.3, No.4, December 2011

An example of radio labeling of $\mathrm{FW}^{4}$ is shown in Figure 1.

In the next theorem we will find the lower bound for the radio number ofFW ${ }^{\mathrm{k}}$.

Theorem 3.2.For $k \geq 4$ and $n \geq 5$,

$$
r n\left(F W^{k}\right) \geq t k+9 k+2
$$

wherek is the number of copies of Wheel, $\mathrm{n}$ is the number of vertices in each copy of the Wheel and $t$ be the number of vertices which are non-adjacent to the central vertex.

Proof.Assume $\mathrm{k} \geq 4$. Since $\operatorname{diam}\left(\mathrm{F} \mathrm{W}_{n}^{\mathrm{k}}\right)=4$, so any radio labeling $\mathbf{f}$ of $\mathrm{FW}_{n}^{\mathrm{k}}$ must satisfy the radio condition i.e.

$$
\mathrm{d}(\mathrm{u}, \mathrm{v})+|\mathbf{f}(\mathrm{u})-\mathbf{f}(\mathrm{v})| \geq 5
$$

holds for all distinct $\mathrm{u}, \mathrm{v} \in \mathrm{V}\left(\mathrm{F} \mathrm{W}_{n}^{\mathrm{k}}\right)$. Now we count the total number ofrestricted values:

Restricted values associated with any label of $z$ :If $z$ is label asa i.e. $\mathbf{f}(z)=a$, then as

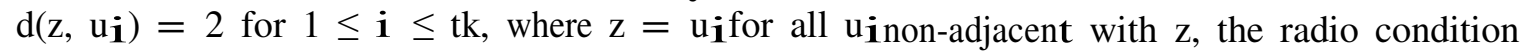
becomes

$\mathrm{d}\left(\mathrm{z}, \mathrm{u}_{\mathbf{i}}\right)+\left|\mathbf{f}(\mathrm{z})-\mathbf{f}\left(\mathrm{u}_{\mathbf{i}}\right)\right| \geq 1+\operatorname{diam}\left(\mathrm{F} \mathrm{W}_{h}^{\mathrm{k}}\right)$, or $2+\left|\mathbf{f}(\mathrm{z})-\mathbf{f}\left(\mathrm{u}_{\mathbf{i}}\right)\right| \geq 1+4$, or $\left|\mathbf{f}(\mathrm{z})-\mathbf{f}\left(\mathrm{u}_{\mathbf{i}}\right)\right| \geq 3$. Hence, the number of restricted values associatedwith any label of $z$ are 2 .

Restricted value associated with any label of the vertices non- adjacent to $\mathrm{z}$ :Since $\mathrm{d}\left(\mathrm{u}_{\mathbf{i}}, \mathrm{u}_{\mathbf{j}}\right) \leq 4$, when $\mathbf{i}=\mathbf{j}$ and for all $1 \leq \mathrm{i}, \mathbf{j} \leq \mathrm{tk}-1$. The radio condition becomes

$\mathrm{d}\left(\mathrm{u}_{\mathbf{i}}, \mathrm{u}_{\mathbf{j}}\right)+\left|\mathbf{f}\left(\mathrm{u}_{\mathbf{i}}\right)-\mathbf{f}\left(\mathrm{u}_{\mathbf{j}}\right)\right| \geq 5$, or $4+\left|\mathbf{f}\left(\mathrm{u}_{\mathbf{i}}\right)-\mathbf{f}\left(\mathrm{u}_{\mathbf{j}}\right)\right| \geq 5$, or $\left|\mathbf{f}\left(\mathrm{u}_{\mathbf{i}}\right)-\mathbf{f}\left(\mathrm{u}_{\mathbf{j}}\right)\right| \geq 1$. It means we can assign consecutive integers to $\mathbf{u} \mathbf{i}$, which implies that there are no restricted value associated with any labelof $u_{\mathbf{i}}$.

Restricted value associated with any label of the vertex utknon- adjacent to $\mathbf{z}$ :Suppose $\mathrm{d}\left(\mathrm{u}_{\mathrm{tk}}, \mathrm{v} \mathbf{i}\right) \leq 3$ for $1 \leq \mathbf{i} \leq 3 \mathrm{k}$, where $\mathrm{u}_{\mathrm{tk}}=\mathrm{v}_{\mathbf{i}}$ andfor all $\mathrm{v} \mathbf{i}$ adjacent to $\mathrm{z}$, the radio condition in this case will be

$\mathrm{d}\left(\mathrm{utk}_{\mathrm{tk}}, \mathrm{v} \mathbf{i}\right)+\left|\mathbf{f}\left(\mathrm{utk}_{\mathrm{tk}}\right)-\mathbf{f}(\mathrm{v} \mathbf{i})\right| \geq 5$, or $3+\left|\mathbf{f}\left(\mathrm{utk}_{\mathrm{tk}}\right)-\mathbf{f}(\mathrm{v} \mathbf{i})\right| \geq 5$,or $\mid \mathbf{f}($ utk $)-\mathbf{f}(\mathrm{v} \mathbf{i}) \mid \geq 2$. So, there is only one restricted value corresponding to utk.

Restricted values associated with any label of the vertices ad- jacent to the central vertex:Since $v_{\mathbf{i}}$ denote any vertex adjacent to $z$.If $d\left(v_{\mathbf{i}}, v_{\mathbf{j}}\right) \leq 2$, when $v_{\mathbf{i}}=v_{\mathbf{j}}$ for $1 \leq i, \mathbf{j}$ $\leq 3 \mathrm{k}$. Then, the radio conditionbecomes

$\mathrm{d}\left(\mathrm{v} \mathbf{i}, v_{\mathbf{j}}\right)+\left|\mathbf{f}\left(\mathrm{v}_{\mathbf{i}}\right)-\mathbf{f}\left(\mathrm{v}_{\mathbf{j}}\right)\right| \geq 1+4$, or $2+\left|\mathbf{f}\left(\mathrm{v}_{\mathbf{i}}\right)-\mathbf{f}\left(\mathrm{v}_{\mathbf{j}}\right)\right| \geq 5$, or $\left|\mathbf{f}\left(\mathrm{v}_{\mathbf{i}}\right)-\mathbf{f}\left(\mathrm{v}_{\mathbf{j}}\right)\right| \geq 3$. Therefore, restricted values associated with each label of viare2. Since we have two restricted values for each $3 \mathrm{k}-1$ vertices. Hence, the total restricted values in this case will be $2(3 \mathrm{k}-1)$. 
International journal on applications of graph theory in wireless ad hoc networks and sensor networks

(GRAPH-HOC) Vol.3, No.4, December 2011

\section{Total number of restricted values associated with any label of $\mathrm{FW}^{\mathbf{k}}{ }_{\boldsymbol{r}}$}

Total number of restricted values associated with any label of $\mathrm{FW}_{n}$ will be the sum of restricted value associated with $\mathrm{z}+$ restricted value associated with $\mathrm{u}_{\mathbf{i}}+$ restricted value associated with $\mathbf{u t k}^{+}$ restricted value associatedwith $v_{\boldsymbol{i}}=2+0+1+2(3 k-1)=6 k+1$

Hence, $\operatorname{rn}\left(\mathrm{F} \mathrm{W}_{n}^{\mathrm{k}}\right) \geq$ allowed values + restricted values

$$
\begin{aligned}
& =(t+3) k+1+6 k+1, \\
& =t k+9 k+2 .
\end{aligned}
$$

Hence, we establish the lower bound for the radio number of $F W^{k} . \quad n$
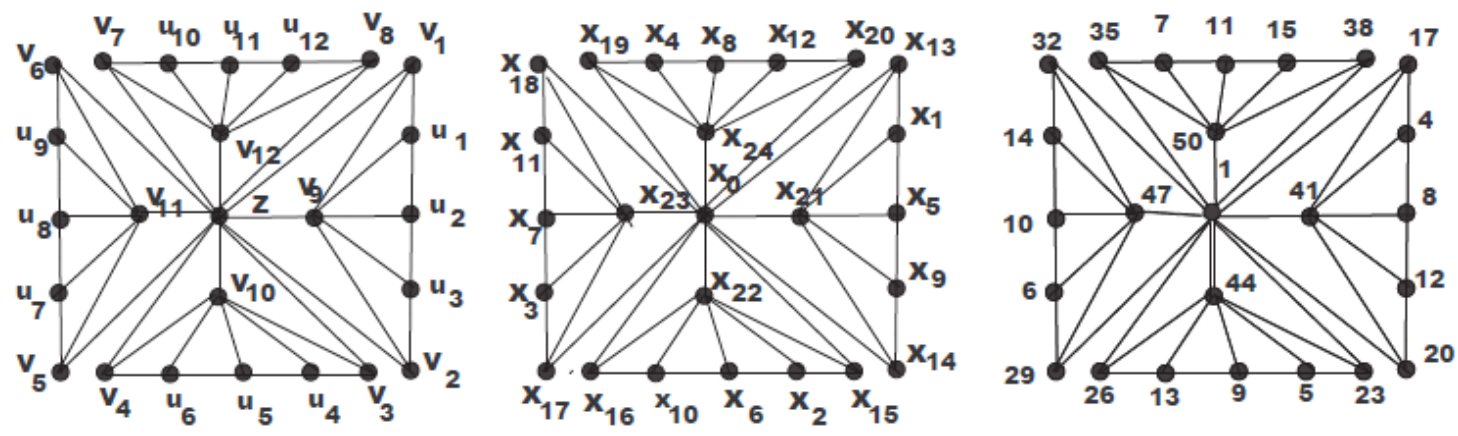

Figure 2.Relabeling and Radio labeling of $\mathrm{FW}^{4}$

Our next result will give the upper bound for the radio number of $\mathrm{FW}^{\mathrm{k}}$. $n$

Theorem 3.3. For $k \geq 4$ and $n \geq 5, r n\left(F W^{k}{ }_{d} \leq t k+9 k+2\right.$.

Proof. If $\mathbf{f}$ is any radio labeling of $\mathrm{FW}_{n}^{\mathrm{k}}$; then span of this labeling will provide an upper bound for the radio number of $\mathrm{FW}^{\mathrm{k}}$ in $\mathrm{In}$ order to find an upper bound firstly we define the position function $\mathrm{p}$ that renames the 
International journal on applications of graph theory in wireless ad hoc networks and sensor networks

(GRAPH-HOC) Vol.3, No.4, December 2011

vertices of $F W_{n}^{k}$ using the set $\left\{x_{0}, x_{1}, \ldots, x_{(t+3) k}\right\}$. Then we specify the labels $f\left(x_{i}\right)$ so that $i<j$ if and only if $f(i)<f(j)$. For $k \geq 2$ and $n \geq 5$, the position function $p: V\left(F W_{n}^{k}\right) \rightarrow\left\{x_{0}, x_{1}, \ldots, x_{(t+3) k}\right\}$ is defined as follows:

$p(z)=x_{0}$.

For $1 \leq j \leq t, \quad p\left(u_{j+t(i-1)}\right)=x_{i+(j-1) k}$, where $1 \leq i \leq k$ and $p\left(v_{i}\right)=x_{t k+i}$ for $1 \leq i \leq 3 k$.

Next, we define a radio labeling $f:\left\{x_{0}, x_{1}, \ldots, x_{(t+3) k}\right\} \rightarrow Z^{+}$as follows:

$$
f\left(x_{i}\right)=\left\{\begin{array}{lll}
1, & \text { for } & i=0 ; \\
3+i, & \text { for } & 1 \leq i \leq t k ; \\
t k+2+3(i-t k), & \text { for } & t k+1 \leq i \leq(t+3) k .
\end{array}\right.
$$

Claim:The labeling $\mathbf{f}$ is a valid radio labeling. Wehave to show that the radio condition

$$
\mathrm{d}(\mathrm{u}, \mathrm{v})+|\mathbf{f}(\mathrm{u})-\mathbf{f}(\mathrm{v})| \geq 1+\operatorname{diam}\left(\mathrm{F} \mathrm{W}_{n}^{\mathrm{k}}\right) \geq 5
$$

must holds for all pair of vertices $(\mathrm{u}, \mathrm{v})$, where $\mathrm{u}=\mathrm{v}$.

Case 1:Consider the pair $(z, r)$, when $z=r$ for all $r \in V\left(F W^{k}\right)_{i}$ Since

$\mathrm{d}(\mathrm{z}, \mathrm{r}) \leq 2, \mathrm{p}(\mathrm{z})=\mathrm{x} 0$ and $\mathrm{p}(\mathrm{r})=\mathrm{x} \mathbf{i}$ for $1 \leq \mathbf{i} \leq(\mathrm{t}+3) \mathrm{k}$. Therefore, $\mathbf{f}(\mathrm{x} \mathbf{i}) \geq 4$ for all $1 \leq \mathbf{i} \leq$ $(\mathrm{t}+3) \mathrm{k}$ and $\mathbf{f}(\mathrm{z})=1$. So, the radio conditionbecomes

$d(z, r)+|f(z)-f(r)| \geq 2+|1-4|$, or $d(z, r)+|f(z)-f(r)| \geq 5$.

Hence, the radio condition is satisfied.

Case 2:Consider the pair of vertices $\left(v_{\mathbf{i}}, v_{\mathbf{j}}\right)$, where $1 \leq \mathrm{i}, \mathbf{j} \leq 3 \mathrm{k} . \operatorname{Asd}\left(\mathrm{v}_{\mathbf{i}}, \mathrm{v}_{\mathbf{j}}\right) \leq 2$, the label difference for each pair will be

$\left|\boldsymbol{f}\left(v_{\boldsymbol{i}}\right)-\boldsymbol{f}\left(v_{\boldsymbol{j}}\right)\right|=\left|\boldsymbol{f}\left(x_{\boldsymbol{t}} \boldsymbol{k}+\boldsymbol{i}\right)-\boldsymbol{f}\left(x_{\boldsymbol{t}} \boldsymbol{k}+\boldsymbol{j}\right)\right|=|t k+2+3(\boldsymbol{i}-t k)-t k-2-3(\boldsymbol{j}-t k)|$

$\left|\boldsymbol{f}\left(v_{\boldsymbol{i}}\right)-\boldsymbol{f}\left(v_{\boldsymbol{j}}\right)\right|=3|\boldsymbol{i}-\boldsymbol{j}| \geq 3$. The radio condition becomes

$\mathrm{d}\left(\mathrm{v}_{\mathbf{i}}, \mathrm{v}_{\mathbf{j}}\right)+\left|\mathbf{f}\left(\mathrm{v}_{\mathbf{i}}\right)-\mathbf{f}\left(\mathrm{v}_{\mathbf{j}}\right)\right| \geq 2+3=5$.

Hence, the radio condition is satisfied.

Case 3:Since $\mathrm{d}\left(\mathrm{u}_{\mathbf{i}}, \mathrm{u}_{\mathrm{W}}\right) \leq 4$ for $1 \leq \mathrm{i}, \mathrm{w} \leq \mathrm{tk}$, therefore

$\left|\boldsymbol{f}\left(u_{\boldsymbol{j}}+\boldsymbol{t}(\boldsymbol{i}-1)\right)-\boldsymbol{f}\left(u_{\boldsymbol{j}}+\boldsymbol{t}(w-1)\right)\right|=\left|\boldsymbol{f}\left(x_{\boldsymbol{i}}+(\boldsymbol{j}-1) k\right)-\boldsymbol{f}\left(x_{w}+(\boldsymbol{j}-1) k\right)\right|$

$=|3+\boldsymbol{i}+(\boldsymbol{j}-1) k-3-w-(\boldsymbol{j}-1) k|$

$\left|\boldsymbol{f}\left(u_{\boldsymbol{i}}\right)-\boldsymbol{f}\left(u_{w}\right)\right|=|\boldsymbol{i}-w| \geq 1$. Hence, the radio condition becomes

$d\left(u_{\boldsymbol{i}}, u_{w}\right)+\left|\boldsymbol{f}\left(u_{\boldsymbol{i}}\right)-\boldsymbol{f}\left(u_{w}\right)\right| \geq 4+1=5$.

Hence, the radio condition is satisfied. 
International journal on applications of graph theory in wireless ad hoc networks and sensor networks

(GRAPH-HOC) Vol.3, No.4, December 2011

Case 4:Consider the pair $\left(\mathrm{v}_{\mathbf{i}}, \mathrm{u}_{\mathrm{w}}\right)$, where $\mathbf{i}=\mathrm{w}$. As $d\left(v_{\boldsymbol{i}}, u_{w}\right) \leq 3$ for $1 \leq \boldsymbol{i} \leq 3 k$ and $1 \leq w \leq$ $t k$. Wehave $\mathbf{f}\left(\mathrm{u}_{\mathrm{W}}\right) \in\{4,5, \ldots, \mathrm{tk}+3\}$ and $\mathbf{f}(\mathrm{v} \mathbf{i}) \in\{\mathrm{tk}+5, \mathrm{tk}+8, \ldots, \mathrm{tk}+9 \mathrm{k}+2\}$. The possible label difference foreach pairs are,

$\left|\boldsymbol{f}\left(v_{\boldsymbol{i}}\right)-\boldsymbol{f}\left(u_{w}\right)\right|=|t k+5-t k-3|=2$,

$\left|\boldsymbol{f}\left(v_{\boldsymbol{i}}\right)-\boldsymbol{f}\left(u_{w}\right)\right|=|t k+9 k+2-4|=t k+9 k-2$.

So, $\left|\boldsymbol{f}\left(v_{\boldsymbol{i}}\right)-\boldsymbol{f}\left(u_{w}\right)\right| \geq 2$. The radio condition becomes

$d\left(v_{\boldsymbol{i}}, u_{w}\right)+\left|\boldsymbol{f}\left(v_{\boldsymbol{i}}\right)-\boldsymbol{f}\left(u_{w}\right)\right| \geq 3+2=5$.

Hence, the radio condition is satisfied. These four cases establish the claim

that $\mathbf{f}$ is a valid radio labeling of $\mathrm{FW}^{\mathrm{k}}{ }_{n}$

Thus, $r\left(\mathrm{FW}_{n}^{\mathrm{k}}\right) \leq \operatorname{span}(\mathbf{f})=\mathrm{tk}+9 \mathrm{k}+2$.

An example of radio labeling of $\mathrm{FW}^{4}$ is shown in Figure 2.

Combing Theorem 3.2 and Theorem 3.3 we have.

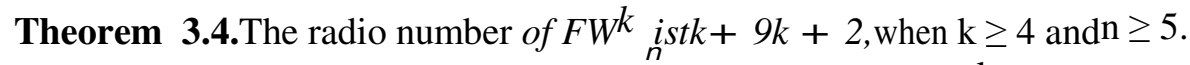

Note:It is easy to see that weget the same radio number of $\mathrm{FW}_{n}{ }_{n}$ for $\mathrm{k}=2$ and $\mathrm{k}=3$ as given in Theorem 3.3 but we cannot follow the above procedure.

The radio number of $\mathrm{k}$-Wheel $\operatorname{graph}(\mathrm{kW})$ : In thissection we will find the radio number of $\mathrm{k}$ Wheel graph $(\mathrm{kW})$ defined as follows: For $\mathrm{k}=1$ we have 1-Wheel graph which is isomorphic to Wheel graph and its radio number is given by [3], for $\mathrm{k} \geq 2$ consider $\mathrm{k}$ concentric cycles of arbitrary length

and join each vertex of the concentric cycles with the center $\left(\mathrm{K}_{1}\right)$. The re- sulting graph denoted by $\mathrm{kW}$ is isomorphic to $\left\{\mathrm{C}_{1} \mathrm{C}_{2} \cdots \mathrm{C}_{\mathrm{k}}\right\}+\mathrm{K}_{1}$, where $\mathrm{K}_{1}$ is a complete graph having one vertex. Itseasy to see that num ber of vertices in $\mathrm{kW}$ areli +1 , where $11 \geq 12 \geq \cdots \geq 1_{\mathrm{k}}$ denotethe length of the cycles $\mathrm{C}_{\mathbf{i}}$ for $1 \leq \mathbf{i} \leq \mathrm{k}$ respectively and $\operatorname{diam}(\mathrm{kW})=2$. The labeling of $\mathrm{kW}$ is defined as follows: The central vertex(hub) is labeled as $\mathrm{z}$, the vertices adjacent to the center are labeled sequentially by $\{\mathrm{v} 1, \mathrm{v} 2$, . . . , vk $\}$.We start labeling from the outer most cycle which has largest length(11). An example for 3 -Wheel $\operatorname{graph}(3 \mathrm{~W})$ is shown inFigure 3. Wedenote number of concentric cycles by k.In the next theorem we will determine the lower bound for $\mathrm{rn}(\mathrm{kW})$.

Theorem 3.5.For $\mathrm{k} \geq 2$, we havek

$$
r n(k W) \geq \sum_{i=1}^{k} l_{i}+2,
$$

Where $\mathbf{l}_{\mathbf{i}}$ are the length of concentric cycles. 
International journal on applications of graph theory in wireless ad hoc networks and sensor networks

(GRAPH-HOC) Vol.3, No.4, December 2011

Proof.Since diam $(\mathrm{kW})=2$ for any positive integer $\mathrm{k}$. Wehave the radio condition $\mathrm{d}(\mathrm{u}, \mathrm{v})+\mid \mathbf{f}(\mathrm{u})$ - $\mathbf{f}(\mathrm{v}) \mathrm{I} \geq 3$ for all distinct $\mathrm{u}, \mathrm{v} \in \mathrm{V}(\mathrm{kW})$, where fis the radio labeling of $\mathrm{kW}$. First of all we will count the minimum number of restricted labels which will eventually give us the lower bound for the radio number of $\mathrm{kW}$.

Restricted value associated with $z$ :Let $u$ takef $(z)=b$, whereb $\in Z^{+}$. Since $d(z, v \mathbf{j})=1$ for all $\mathrm{z}=\mathrm{v} \mathbf{j}$, where $1 \leq \mathbf{j} \leq \mathbf{l}_{\mathbf{i}}$, then $\mathrm{b}+1$ is the restricted label associated with $\mathrm{z}$.

Restricted value associated with $v_{\mathbf{j}}: A s d\left(v_{\mathbf{j}}, v_{W}\right) \leq 2$ for all $v_{\mathbf{j}}=v_{W}$, where $1 \leq \mathbf{j}, w \leq \mathbf{l}_{\mathbf{i}}$, we will have two cases.

When $l_{1}=l_{2}=\cdots=l_{k}$ :There exist no restricted value associatedwith $v_{\mathbf{j}}$, where $1 \leq \mathbf{j} \leq \mathbf{l}_{\mathbf{i}}$ i.e. we can assign theconsecutive integersto $v \mathbf{j}$.

When $l_{1} \geq l_{2} \geq \cdots \geq l_{k}$ :There exist no restricted value associated with $v_{\mathbf{j}}$, where $1 \leq \mathbf{j} \leq \mathbf{l}_{\mathbf{i}}$ i.e. we can assign theconsecutive integersto $v_{\mathbf{j}}$.

So, there exist only one restricted value associated with any label of $\mathrm{kW}$.

The total number of allowed labels are,

$l_{i}+1$ for $l_{1}=l_{2}=\cdot \cdot \cdot=l_{k a n d l} \geq l_{2} \geq \cdot \cdot \cdot \geq l_{k}$.

Hence, the radio number of $\mathrm{kW} \geq$ allowed values + restricted value

i.e. $\operatorname{rn}(\mathrm{kW}) \geq$

whichestablish the lower bound for $\mathrm{rn}(\mathrm{kW})$.

Our next theorem will give the upper bound for $\mathrm{rn}(\mathrm{kW})$.

Theorem 3.6.For $\mathrm{k} \geq 2$, we have

where $\mathbf{i}$ are the length of the concentric cycles.

Proof.We will define our radio labeling $\mathbf{f}: \mathrm{V}(\mathrm{kW}) \rightarrow \mathrm{Z}^{+}$which will havea minimum span $=$ $\mathbf{k}_{\mathbf{1}}+2$ is defined as follows:

Step1: We start labeling from the central vertex z. Let $\mathbf{f}(\mathrm{z})=1$.

Step2: After labeling $\mathrm{z}$ we move to $\mathbf{v} \mathbf{j}$, where $1 \leq \mathbf{j} \leq \mathbf{l}_{\mathbf{i}}$. We canstart labeling from any $v_{\mathbf{j}} \operatorname{let} \mathbf{f}\left(v_{\mathbf{j}}\right)=3$. In order to label $v_{\mathbf{j}}$ we will considerthose vertices which has distance twobetween them i.e. if $\mathrm{d}\left(\mathrm{v}_{\mathbf{j}}, \mathrm{v}_{\mathrm{W}}\right)=2$, where $1 \leq \mathbf{j}, \mathrm{w} \leq \mathbf{1}_{\mathbf{i}}$ and $\mathbf{j}=\mathrm{w}$ then we can assign consecutive integerto $v \mathbf{j}$ and $v_{\mathrm{W}}$ so that the radio condition is satisfied. For $\mathrm{k}=3$ the radio labeling of $\mathrm{kW}$ defined above is illustrated in Figure 3. 
International journal on applications of graph theory in wireless ad hoc networks and sensor networks

(GRAPH-HOC) Vol.3, No.4, December 2011

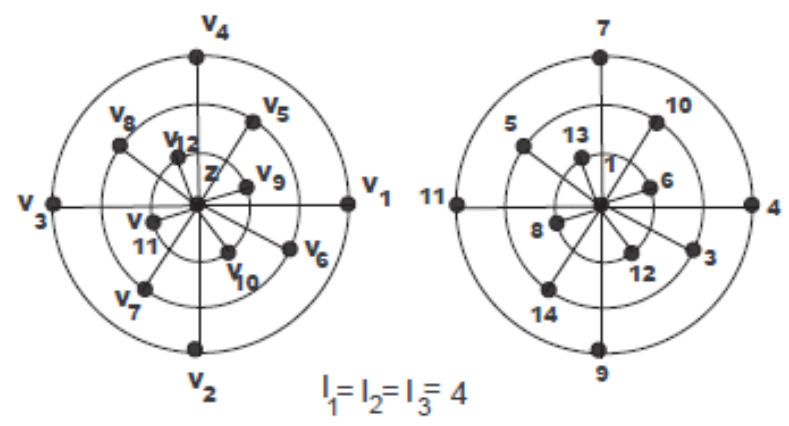

\begin{tabular}{|c|c|c|c|c|}
\hline$I^{\prime}$ & 1 & 2 & 3 & 4 \\
\hline 1st & $v_{1}{ }_{4}$ & $v_{2}$, & $v_{3}$ & $v_{4}$ \\
\hline 2nd & $\begin{array}{l}V_{5} \\
10\end{array}$ & $v_{6}$ & $v_{7}$ & $v_{8}$ \\
\hline 3rd & $v_{9}$ & $\begin{array}{l}K_{10} \\
12\end{array}$ & $\mathrm{v}_{11}$ & $\mathrm{v}_{12}$ \\
\hline
\end{tabular}

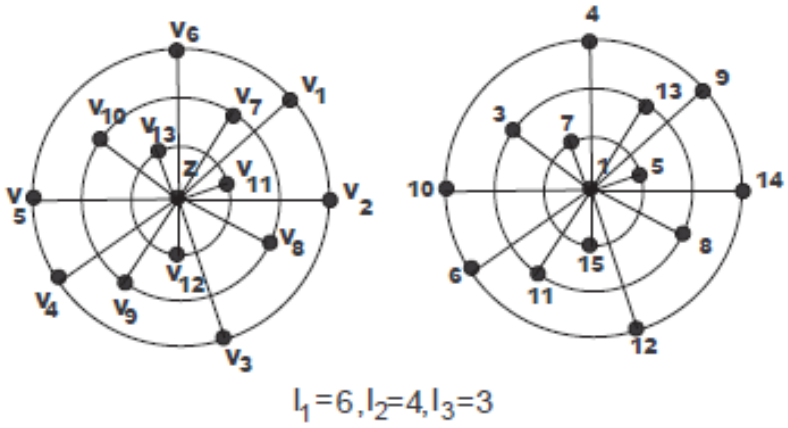

\begin{tabular}{|c|c|c|c|c|c|c|}
\hline$k^{\text {th }} I^{i}$ & 1 & 2 & 3 & 4 & 5 & 6 \\
\hline $1_{\mathrm{st}}$ & $v_{1}$ & $\begin{array}{l}v_{2} \\
14\end{array}$ & $\begin{array}{l}V_{3} \\
12\end{array}$ & $v_{4}$ & $v_{5}$ & $v_{6}$ \\
\hline 2nd & $v_{7}$ & $v_{8}$ & $v_{9}$ & $\begin{array}{r}v_{10} \\
3\end{array}$ & & \\
\hline $3 \mathrm{rd}$ & $\begin{array}{r}v_{11} \\
5\end{array}$ & $\begin{array}{c}V_{12} \\
15 \\
\end{array}$ & $v_{13}$ & & & \\
\hline
\end{tabular}

Figure 3. Radio labeling of $3 \mathrm{~W}$

Claim:f is a radio labeling. We must show that the radio conditiond $(u, v)+|\boldsymbol{f}(u)-\boldsymbol{f}(v)| \geq$ $\operatorname{diam}(G)+1 \geq 3$ holds for all pair of vertices $(u, v)$ (where $\mathrm{u}=\mathrm{v})$. We will have two cases:

Case 1:Consider the pair $\left(\mathrm{z}, \mathrm{v}_{\mathbf{j}}\right)$, where $z=v_{\boldsymbol{j}}$ for $1 \leq \boldsymbol{j} \leq \boldsymbol{l}_{\boldsymbol{i}}$. Since $d\left(z, v_{\boldsymbol{j}}\right)=1, \boldsymbol{f}(z)=1$ and $\boldsymbol{f}\left(v_{\boldsymbol{j}}\right) \geq 3$ for all $l \leq \boldsymbol{j} \leq \boldsymbol{l}_{\boldsymbol{i}}$. Examining the label difference for each pair, we have $\left|\mathbf{f}(\mathrm{z})-\mathbf{f}\left(\mathrm{v}_{\mathbf{j}}\right)\right| \geq$ 2.So, the radio condition becomes $d(z, v \mathbf{j})+\left|\mathbf{f}(z)-\mathbf{f}\left(v_{\mathbf{j}}\right)\right| \geq 1+2=3$. Hence, the radio condition is satisfied in this case.

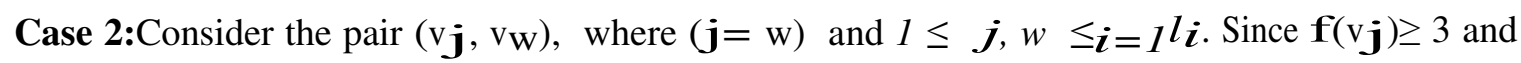
$\mathrm{d}\left(\mathrm{v}_{\mathbf{j}}, \mathrm{v}_{\mathrm{W}}\right) \leq 2$. So, the label difference will belf $\boldsymbol{f}\left(v_{\boldsymbol{j}}\right)-\boldsymbol{f}\left(v_{\boldsymbol{w}}\right) \mid \geq 1$ for all distinct $v_{\boldsymbol{j}}, v_{\boldsymbol{w}}$. The radio condition for such pairof vertices becomes $d\left(v_{\boldsymbol{j}}, v_{w}\right)+\left|\boldsymbol{f}\left(v_{\boldsymbol{j}}\right)-\boldsymbol{f}\left(v_{w}\right)\right| \geq 2+1=3$. Hence, the radio condition is satisfied.

These twocases establish the claim that $\mathbf{f}$ is a valid radio labeling of $\mathrm{kW}$.Thus, $\mathbf{r n}(\mathrm{kW}) \leq \operatorname{span}(\mathbf{f})$ $=\mathbf{l}_{\mathbf{i}}+2$.

Note:In Figure 3 when $11=12=13=4$ we start labeling from v6 i.e. $\mathbf{f}\left(v_{6}\right)=3$. After labeling v6 we move to v1 because $\mathrm{d}(\mathrm{v} 6, \mathrm{v} 1)=2$ so, we can assign the consecutive integer to v1 i.e. $\mathbf{f}(\mathrm{v} 1)=$ 4. After labeling $\mathrm{v}_{1}$ we move to $\mathrm{v}_{8}$ because $\mathrm{d}\left(\mathrm{v}_{8}, \mathrm{v}_{1}\right)=2$ so, we can assign the consecutive integer to v8 i.e. $\mathbf{f}(\mathrm{v} 8)=5$. We continue in the same way and label all the vertices of $\mathrm{kW}$. Similarly, when $11=6,12=4$ and $13=3$ we start labeling from v10 i.e. $\mathbf{f}(\mathrm{v} 10)=3$. After labeling $\mathrm{v} 10$ we move to $\mathrm{v} 6$ because $\mathrm{d}(\mathrm{v} 10, \mathrm{v} 6)=2$ so, we can assign the consecutive integer to v6 i.e. $\mathbf{f}(\mathrm{v} 6)=4$. After labeling $\mathrm{v} 6$ we move to $\mathrm{v} 11$ because $\mathrm{d}(\mathrm{v} 11, \mathrm{v} 6)=2$ so, we can assign the consecutive integer to $\mathrm{v} 11$ i.e. $\mathbf{f}(\mathrm{v} 11)=5$. We continue in the same way and label all the vertices of $\mathrm{kW}$. 
International journal on applications of graph theory in wireless ad hoc networks and sensor networks (GRAPH-HOC) Vol.3, No.4, December 2011

Theorem 3.7.If $\mathrm{kW}$ is a $\mathrm{k}-\mathrm{Wheel}$ graph, then

$$
r n(k W)=\sum_{i=1}^{k} l_{i}+2,
$$

where $\mathbf{l}_{\mathbf{i}}$ are the length of the concentric cycles.

Proof.Follows from Theorem 3.5 and Theorem 3.6.

The radio number ofJoint-Wheel graph $\left(\mathrm{W}_{\mathbf{n}}\right)$ : Joint-Wheel graph $\left(\mathrm{W} \mathrm{H}_{\mathbf{n}}\right)$ is defined as follows: It consist two disjointcopies of Wheel which are joined by an edge between two rim vertices. It is easy to note that $\mathrm{WH}_{n}$ has $2 n+2$ vertices and $4 n+1$ edges, where $n$ is the number of rimvertices in one copy of the Wheel graph. Itseasy to see that for $n \geq 4$, diam $\left(W_{n} H_{n}\right)=5$.

The labeling of Joint-Wheel is defined as follows:

To establish the radio number of Joint-Wheel we will define a labeling for the vertices of $\mathrm{WH}_{\mathbf{n}}$ that distinguishes the vertices by their characteristics. The hub vertices are labeled as $\mathrm{z}_{1}$ and $\mathrm{z} 2$, the vertices adjacent to $\mathrm{z}_{1}$ and $\mathrm{z}_{2}$ are labeled sequentially by $\left\{\mathrm{v} 1, \mathrm{v} 2, \ldots, \mathrm{v}_{\mathbf{n}}\right\}$ in counterclockwise directionand by $\left\{u_{1}, u_{2}, \ldots ., u_{n}\right\}$ in clockwise direction respectively. Wespecify that $v_{1}, v_{n}-1$ are adjacent to $v_{n}$ and $u_{1}, u_{n}-1$ are adjacent to $u_{n}$, also $v_{n}$ andun are the end vertices of the bridge(between twocopies of Wheel graph).

Theorem 3.8.For every $n \geq 10$,

$$
r n\left(W H_{n}\right) \geq 4 n+7
$$

Proof. Since diam $\left(\mathrm{W} \mathrm{H}_{\mathbf{n}}\right)=5$, we must show that the radio conditiond $(\mathrm{u}, \mathrm{v})+|\mathbf{f}(\mathrm{u})-\mathbf{f}(\mathrm{v})| \geq$ 6 holds for every twodistinct vertices $\mathrm{u}, \mathrm{v} \in \mathrm{V}\left(\mathrm{W} \mathrm{H} \mathrm{H}_{\mathbf{n}}\right)$. We start labeling from the vertices $\mathrm{v} 2$ and $\mathrm{u}_{2}$. If we assume that $\mathbf{f}\left(\mathrm{v}_{2}\right)=\mathrm{a}$ and $\mathbf{f}\left(\mathrm{u}_{2}\right)=\mathrm{a}+1$. Then it may be noted that whenever we assign an integer to one copy of Wheelwe must assign the next possible integerto the second copy of Wheel. We will discuss even and odd cases separately.

When nis even:Since we start labeling from $v_{2}$ and $u_{2}$ i.e. $\mathbf{f}\left(v_{2}\right)=$ aand $\mathbf{f}\left(u_{2}\right)=a+1$. So, there exist no restricted value associated with v2. After labeling u2 we move to vi , where $1 \leq \mathbf{i} \leq \mathrm{n}$ and $\mathbf{i}=2$, if $\mathbf{f}\left(v_{\mathbf{n}}\right)=\mathrm{a}+4$ then there exist two restricted values associated with $\mathrm{u}_{2}$. After assigning label to $v_{n}$ we label $u_{3}$ i.e. $\mathbf{f}\left(u_{3}\right)=a+7$. So, there are two restricted val- ues associated with $\mathbf{v}_{\mathbf{n}}$. Following in the similar way we can see that there exist two restricted values associated with each vertex of the following set $\left\{u_{2}, v_{n}, v_{3}, u_{n}, u 4\right\}$.

Consider the pair $(v 2 \boldsymbol{i}+2, u 2 \boldsymbol{j}-1)$. Since $d(v 2 \boldsymbol{i}+2, u 2 \boldsymbol{j}-1) \leq 5$, where $2 \leq \boldsymbol{i} \leq 1 \leq \boldsymbol{j} \leq 2^{\text {and }} \boldsymbol{j}$ $=2$. If $\boldsymbol{f}(v 6)=b$ (the value of $\mathrm{b}$ must be great thanpreviously assign integer) then $\boldsymbol{f}(u 1)=b+2$ i.e. $b+l$ is the restrictedvalue for the remaining $v_{\mathbf{i}}$ and $\mathrm{u}_{\mathbf{j}}$, where $3 \leq \boldsymbol{i} \leq$ and $3 \leq \boldsymbol{j} \leq \underline{n}$. 
International journal on applications of graph theory in wireless ad hoc networks and sensor networks (GRAPH-HOC) Vol.3, No.4, December 2011

So, there exist one restricted value associated with v6. Now we will moveto the first copy of wheel. After labelingf $\left(u_{1}\right)=b+2$ we assign $b+4$ to v8 i.e. there exist one restricted value associated ithu1. Following inthe similar way we can see that there exist one restricted value associatedwith eachv $2 \mathbf{i}+2$ and $\mathbf{u}_{2} \mathbf{j}-1$, where 2 and $\mathbf{j}=2$.Therefor, total number of restricted values associated with $v 2 \mathbf{i}+2$ areand restricted values associated with $\mathbf{u} 2 \mathbf{j}-1$ are. Similarly we consider

the pair of vertices restricted values associated with $\mathrm{u}_{2} \mathbf{j}+2$ are

Since $\mathrm{d}\left(\mathrm{u}_{\mathrm{n}}-2, \mathrm{z} 1\right)=4$, the radio condition becomes

$d\left(u_{n}-2, z 1\right)+\left|f\left(u_{n}-2\right)-f(z 1)\right| \geq 6$, or $\left|f\left(u_{n}-2\right)-f(z 1)\right| \geq 2$,

whichimplies that there exist two restricted values associated with $\mathrm{u}_{\mathrm{n}}-2$. If $\mathrm{z} 1$ is labeled as $\mathrm{c}($ the value of $\mathrm{c}$ must be great than previously assigninteger), then any positive value from the set $\{\mathrm{c}+$ $1, c+2\}$ assigned to $z 2$ will not satisfy the radio condition which is defined above for the pair of vertices $\left(\mathrm{z}_{1}, \mathrm{z} 2\right)$. So, there are two restricted values associated with $\mathrm{z} 1$.

Therefor, the total number of restricted values will be the sum of restricted values associated with $\left\{\mathrm{u}_{2}, \mathrm{v}_{\mathbf{n}}, \mathrm{v}_{3}, \mathrm{u}_{\mathbf{n}}, \mathrm{u} 4\right\}+$ restricted values associated with

$\mathrm{v} 2 \mathbf{i}+2+$ restricted values associated with $\mathbf{u}_{2} \mathbf{j}-1+$ restricted values associated with $\mathrm{v} 2 \mathbf{i}-1+$ restricted values associated with $\mathbf{u}_{2} \mathbf{j}+2+$ restricted values asso- ciated with $\mathrm{u}_{\mathrm{n}}-2+$ restricted values associated with $\mathrm{z} 1$

When nis odd: Since we start labeling from v2 and u2 i.e. $\mathbf{f}\left(\mathrm{v}_{2}\right)=\mathrm{a}$ and $\mathbf{f}\left(\mathrm{u}_{2}\right)=\mathrm{a}+1$. So, there exist no restricted value associated with v2.After labeling $\mathrm{u}_{2}$ we move to $\mathrm{v} \mathbf{i}$, where $1 \leq \mathbf{i} \leq \mathrm{n}$ and $\mathbf{i}$ $=2$, if $\mathbf{f}\left(\mathrm{v}_{\mathbf{n}}\right)=\mathrm{a}+4$ thenthere exist two restricted values associated with $\mathrm{u}_{2}$. After assigning label to $v_{n}$ welabel $u_{3}$ i.e. $\mathbf{f}\left(u_{3}\right)=a+7$. So, there are tworestricted values associated with $v_{n}$. Following in the similar way we can see that there exist two restricted values associated with each vertex of the following $\operatorname{set}\left\{u_{2}, v_{n}, v_{3}, u_{n}, u_{4}\right\}$.

Consider the pair. $\left(\mathrm{v} 2 \mathbf{i}+2, \mathrm{u}_{2} \mathbf{j}_{1}-1\right)$. Since $\mathrm{d}\left(\mathrm{v} 2 \mathbf{i}+2, \mathrm{u}_{2} \mathbf{j}-\underline{n}_{1}\right)^{1} \leq \frac{n-1}{5_{2}}$ where $2 \leq \mathbf{i}_{2} \leq$ than previously $^{2}$ assign integer) then $\mathbf{f}\left(\mathrm{u}_{1}\right) \stackrel{m-1}{=} \mathrm{b}+2$ i.e. $\mathrm{b}+1$ is the restrictedvalue for the remaining $\mathrm{v}_{\mathbf{i}}$ and $\mathrm{u}_{\mathbf{j}}$, where $3 \leq \mathbf{i} \leq$ and $3 \leq \mathbf{j} \leq$ so, there exist one restricted value associated with v6. Now we will moveto the first copy of wheel. After labeling $\mathbf{f}(\mathrm{u} 1)=b+2$ we assign $b+4$ tov8 i.e. there exist one restricted value associated with $\mathrm{u} 1$. Following in thesimilar way we can see that there exist one restricted value associated witheach $v 2 \mathbf{i}+2 \operatorname{andu} 2 \mathbf{j}-1$, where $2 \leq \mathbf{i} \leq$ and $\mathbf{j}=2$. Therefor, total number of restricted values associated with v2i +2 are andrestricted values associated with $\mathrm{u}_{2} \mathbf{j}-1 \operatorname{are}_{2}$. Similarly we consider thepair of vertices $\left(\mathrm{v} 2 \mathbf{i}-1, \mathrm{u}_{2} \mathbf{j}+2\right)$, where $1 \leq \mathbf{i} \leq_{2}$ and $\mathbf{i}=$ $2,2 \leq \mathbf{j} \leq$ applying the above procedure we can found the restricted values associatedwith $\mathrm{v} 2 \mathbf{i}-1$ and $\mathrm{u}_{2} \mathbf{j}+2$. Therefor, total number of restricted values associatedwith $\mathrm{v} 2 \mathbf{i}-1$ are and restricted values associated with $\mathbf{u}_{2} \mathbf{j}+2$ are 
International journal on applications of graph theory in wireless ad hoc networks and sensor networks (GRAPH-HOC) Vol.3, No.4, December 2011

Since $d\left(u_{n}-1, z 1\right)=3$, the radio condition becomes

$$
d\left(u_{n}-1, z 1\right)+\left|f\left(u_{n}-1\right)-f(z 1)\right| \geq 6, \text { or }\left|f\left(u_{n}-1\right)-f(z 1)\right| \geq 3,
$$

whichimplies that there exist two restricted values associated with $\mathrm{u}_{\mathrm{n}}-1$. If $\mathrm{z} 1$ is labeled as $\mathrm{c}$ (the value of $\mathrm{c}$ must be great than previously assigninteger), then any positive value from the set $\{\mathrm{c}+$ $1, c+2\}$ assigned to $\mathrm{z} 2$ will not satisfy the radio condition which is defined above for the pair of

vertices $(\mathrm{z} 1, \mathrm{z} 2)$. So, there are two restricted values associated with $\mathrm{z} 1$.

Therefor, the total number of restricted values will be the sum of restricted values associated with $\left\{u_{2}, v_{\mathbf{n}}, v_{3}, u_{\mathbf{n}}, u_{4}\right\}+$ restricted values associated withv $2 \mathbf{i}+2+$ restricted values associated with $\mathrm{u}_{2} \mathbf{j}-1+$ restricted values associated with $\mathrm{v} 2 \mathbf{i}-1+$ restricted values associated with $\mathrm{u}_{2} \mathbf{j}+2+$ restricted values asso- ciated with $\mathrm{u}_{\mathbf{n}}-1+$ restricted values associated with $\mathrm{z} 1$

Hence, $\mathbf{r n}\left(\mathrm{WH}_{\mathbf{n}}\right) \geq$ allowedvalues+restricted values

$$
=2 n+2+2 n+5, r n\left(W H_{n}\right) \geq 4 n+7 \text {. }
$$

Theorem 3.9.For $n \geq 10$,

$$
r n\left(W H_{n}\right) \leq 4 n+7
$$

Proof.We provide a radio labeling $\mathbf{f}$ of $\mathrm{WH}_{\mathbf{n}}$ for $\mathrm{n} \geq 10$. The span of thislabeling will provide an upper bound for the radio number of $\mathrm{WH}_{\mathbf{n}}$.Starting with any copy of the Wheelsubgraph of $\mathrm{WH}_{\mathbf{n}}$. Radio labelingf $: \mathrm{V}\left(\mathrm{W} \mathrm{H}_{\mathbf{n}}\right) \rightarrow \mathrm{Z}^{+}$is defined as follows:

When nis even:

$$
\begin{array}{lr}
p\left(v_{2}\right)=1, \quad p\left(v_{3}\right)=9, \quad p\left(v_{n}\right)=5, & p\left(v_{1}\right)=2 n+7, \\
p\left(u_{2}\right)=2, \quad p\left(u_{3}\right)=8, \quad p\left(u_{4}\right)=16, & p\left(u_{1}\right)=21, \quad p\left(u_{n}\right)=12, \\
p\left(v_{2 i+2}\right)=15+4(i-1), & \text { for } \quad 1 \leq i \leq \frac{n-4}{2}, \\
p\left(v_{2 i+3}\right)=(2 n+11)+4(i-1), & \text { for } \quad 1 \leq i \leq \frac{n-4}{2}, \\
p\left(u_{2 i+3}\right)=25+4(i-1), & \text { for } \quad 1 \leq i \leq \frac{n-4}{2}, \\
p\left(u_{2 i+4}\right)=(2 n+17)+4(i-1), & \text { for } \quad 1 \leq i \leq \frac{n-6}{2}, \\
p\left(z_{1}\right)=4 n+4, & \\
p\left(z_{2}\right)=4 n+7 . &
\end{array}
$$

When nis even: 
International journal on applications of graph theory in wireless ad hoc networks and sensor networks (GRAPH-HOC) Vol.3, No.4, December 2011

$\begin{array}{lr}p\left(v_{2}\right)=1, \quad p\left(v_{3}\right)=9, \quad p\left(v_{n}\right)=5, & p\left(v_{1}\right)=2 n+9, \\ p\left(u_{2}\right)=2, \quad p\left(u_{3}\right)=8, \quad p\left(u_{4}\right)=16, & p\left(u_{1}\right)=21, \quad p\left(u_{n}\right)=12, \\ p\left(v_{2 i+2}\right)=15+4(i-1), & \text { for } \quad 1 \leq i \leq \frac{n-3}{2}, \\ p\left(v_{2 i+3}\right)=(2 n+13)+4(i-1), & \text { for } \quad 1 \leq i \leq \frac{n-5}{2}, \\ p\left(u_{2 i+3}\right)=25+4(i-1), & \text { for } 1 \leq i \leq \frac{n-5}{2}, \\ p\left(u_{2 i+4}\right)=(2 n+15)+4(i-1), & \text { for } 1 \leq i \leq \frac{n-5}{2}, \\ p\left(z_{1}\right)=4 n+4, & \\ p\left(z_{2}\right)=4 n+7 . & \end{array}$
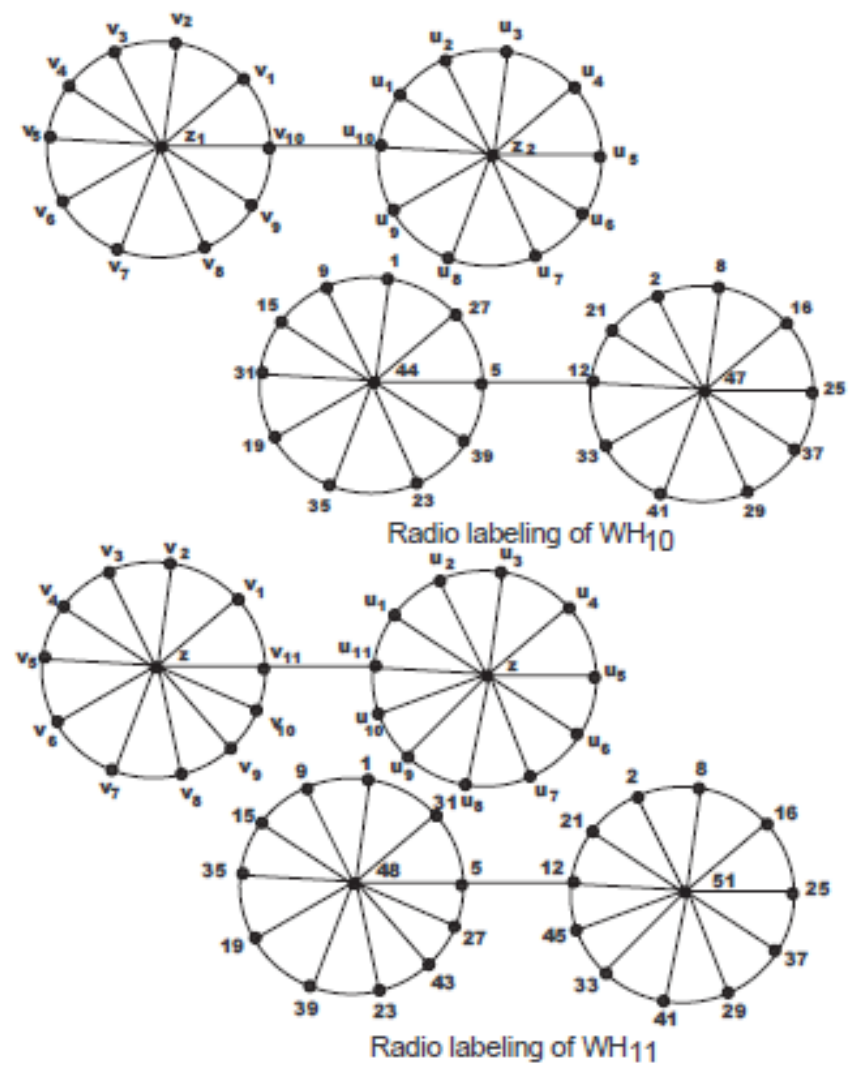

Figure 4

Examples of radio labeling(as define in Theorem 3.9) for $n=10$ and $n=11$ are shown in Figure 4. Claim: The labeling $\mathbf{f}$ is a valid radio labeling i.e. the radio condition

$d(u, v)+|\boldsymbol{f}(u)-\boldsymbol{f}(v)| \geq 1+\operatorname{diam}\left(W H_{n}\right) \geq 6$

must holds for all distinct pairs of vertices of $\mathrm{WH}_{\mathbf{n}}$. We will discuss two cases for $\mathrm{n}$.

When nis even: 
International journal on applications of graph theory in wireless ad hoc networks and sensor networks (GRAPH-HOC) Vol.3, No.4, December 2011

Case 1:In this case we consider the pairs of vertices $\left(v_{\boldsymbol{i}}, v_{\boldsymbol{j}}\right),\left(u_{\boldsymbol{i}}, u_{\boldsymbol{j}}\right)$, where $1 \leq i, \boldsymbol{j} \leq n$. Consider the pair $\left(v_{\boldsymbol{i}}, v_{\boldsymbol{j}}\right)$. As $d\left(v_{\boldsymbol{i}}, v_{\boldsymbol{j}}\right) \leq 2$ and $\boldsymbol{f}\left(v_{\boldsymbol{i}}\right) \in\{1,5,9,15,19, \ldots, 2 n+3,2 n+7,2 n+11$, $\ldots, 4 n-1\}$. The possible label difference for each pair will satisfy $\left|\boldsymbol{f}\left(v_{\boldsymbol{i}}\right)-\boldsymbol{f}\left(v_{\boldsymbol{j}}\right)\right| \geq 4$. So, the radiocondition becomes

$d\left(v_{\boldsymbol{i}}, v_{\boldsymbol{j}}\right)+\left|\boldsymbol{f}\left(v_{\boldsymbol{i}}\right)-\boldsymbol{f}\left(v_{\boldsymbol{j}}\right)\right| \geq 2+4$, or $d\left(v_{\boldsymbol{i}}, v_{\boldsymbol{j}}\right)+\left|\boldsymbol{f}\left(v_{\boldsymbol{i}}\right)-\boldsymbol{f}\left(v_{\boldsymbol{j}}\right)\right| \geq 6$.

Hence, the radio condition is satisfied. Similarly we can check the radio condition for the pair of vertices $\left(u_{\mathbf{i}}, u_{\mathbf{j}}\right)$.

Case 2:In this case we consider the pairs of vertices $(z 1, z 2),\left(z 1, v_{\boldsymbol{i}}\right),\left(z 1, u_{\boldsymbol{i}}\right),\left(z 2, v_{\boldsymbol{i}}\right)$ and $(z 2$, $\left.u_{i}\right)$, where $1 \leq \boldsymbol{i} \leq n$.we will check the radio condition for $\left(z 1, z_{2}\right),\left(z 1, v_{i}\right)$ and $\left(z 1, u_{i}\right)$.

Subcase 2.1: Consider the pair $(z 1, z 2)$. Since $d(z 1, z 2)=3$, the radio condition becomes

$d(z 1, z 2)+|f(z 1)-f(z 2)|=3+|4 n+4-4 n-7|=6$.

Subcase 2.2: Consider the pair $\left(z 1, v_{\boldsymbol{i}}\right)$, where $z 1=v_{\boldsymbol{i}}$. As $d\left(z 1, v_{\boldsymbol{i}}\right)=1$ for $1 \leq \boldsymbol{i} \leq n$. Since $f\left(v_{\boldsymbol{i}}\right) \in\{1,5,9,15,19, \ldots, 2 n+3,2 n+7,2 n+11, \ldots, 4 n-1\}$ and $\boldsymbol{f}(z 1)=4 n+4$. So, the radio condition becomes

$d\left(z 1, v_{\boldsymbol{i}}\right)+\left|\boldsymbol{f}(z 1)-\boldsymbol{f}\left(v_{\boldsymbol{i}}\right)\right| \geq 1+|4 n+4-4 n+1|, \operatorname{ord}\left(z 1, v_{\boldsymbol{i}}\right)+\left|\boldsymbol{f}(z 1)-\boldsymbol{f}\left(v_{\boldsymbol{i}}\right)\right| \geq 6$

Subcase 2.3: Consider the pair $(z 1, u \boldsymbol{i})$, where $z 1=u_{\boldsymbol{i}}$. As $d(z 1, u \boldsymbol{i}) \leq 4$ forl $\leq \boldsymbol{i} \leq n$. Since $\boldsymbol{f}\left(u_{\boldsymbol{i}}\right) \in\{2,8,12,16,21,25, \ldots, 2 n+13,2 n+17, \ldots, 4 n+1\}$ and $\boldsymbol{f}(z 1)=4 n+4$. So, the radio condition becomes

$d\left(z 1, u_{\boldsymbol{i}}\right)+\left|\boldsymbol{f}(z 1)-\boldsymbol{f}\left(u_{\boldsymbol{i}}\right)\right| \geq 4+\mid 4 n+4-4 n-11$, or $d\left(z 1, u_{\boldsymbol{i}}\right)+\left|\boldsymbol{f}(z 1)-\boldsymbol{f}\left(u_{\boldsymbol{i}}\right)\right| \geq 7$,

or $d(z l, u i)+|f(z 1)-f(u i)| \geq 6$.

Hence, the radio condition is satisfied in subcase 2.1,2.2 and 2.3. Similarly

we can check the radio condition for the pairs of vertices $(\mathrm{z} 2, \mathrm{vi})$ and $\left(\mathrm{z} 2, \mathrm{u}_{\mathbf{i}}\right)$.

Case 3:Finally, consider $\left(v_{\boldsymbol{i}}, u_{\boldsymbol{j}}\right)$, where $1 \leq i, \boldsymbol{j} \leq n$. As $d\left(v_{\boldsymbol{i}}, u_{\boldsymbol{j}}\right) \leq 5$ we have $\boldsymbol{f}\left(v_{\boldsymbol{i}}\right) \in\{1,5,9,15$, $19, \ldots, 2 n+3,2 n+7,2 n+11, \ldots, 4 n-1\}$ and $\boldsymbol{f}\left(u_{\boldsymbol{i}}\right) \in\{2,8,12,16,21,25, \ldots, 2 n+13,2 n+$ $17, \ldots, 4 n+1\}$. The labeldif- ferencefor each pair will satisfy $\left|\boldsymbol{f}\left(v_{\boldsymbol{i}}\right)-\boldsymbol{f}\left(u_{\boldsymbol{j}}\right)\right| \geq 1$. So, the radio conditionbecomes

$$
d\left(v_{\boldsymbol{i}}, u_{\boldsymbol{j}}\right)+\left|\boldsymbol{f}\left(v_{\boldsymbol{i}}\right)-\boldsymbol{f}\left(u_{\boldsymbol{j}}\right)\right| \geq 5+1=6 .
$$

When nis odd: 
International journal on applications of graph theory in wireless ad hoc networks and sensor networks

(GRAPH-HOC) Vol.3, No.4, December 2011

Case 1:In this case we consider the pairs of vertices $\left(v_{\boldsymbol{i}}, v_{\boldsymbol{j}}\right)$ and $\left(u_{\boldsymbol{i}}, u_{\boldsymbol{j}}\right)$, where $1 \leq i, \boldsymbol{j} \leq n$. Consider the pair $\left(v_{\mathbf{i}}, v_{\mathbf{j}}\right)$, where $1 \leq i, \boldsymbol{j} \leq n . A s d\left(v_{\boldsymbol{i}}, v_{\boldsymbol{j}}\right) \leq 2$ and $\boldsymbol{f}\left(v_{\boldsymbol{i}}\right) \in\{1,5,9,15,19, \ldots$, $2 n+5,2 n+9,2 n+13, \ldots, 4 n-1\}$. The possible label difference for each pair will satisfy $\left|\boldsymbol{f}\left(v_{\boldsymbol{i}}\right)-\boldsymbol{f}\left(v_{\boldsymbol{j}}\right)\right| \geq 4$. So, the radio condition becomes

$d\left(v_{\boldsymbol{i}}, v_{\boldsymbol{j}}\right)+\left|\boldsymbol{f}\left(v_{\boldsymbol{i}}\right)-\boldsymbol{f}\left(v_{\boldsymbol{j}}\right)\right| \geq 2+4=6$.

Hence, the radio condition is satisfied in this case. Similarly we can check the radio condition for the pair of vertices $\left(u_{\boldsymbol{i}}, u_{\boldsymbol{j}}\right)$ for $1 \leq i, \boldsymbol{j} \leq n$.

Case 2:In this case we consider the pairs of vertices $\left(z 1, z_{2}\right),\left(z_{1}, v_{\boldsymbol{i}}\right),\left(z 1, u_{\boldsymbol{i}}\right),\left(z 2, v_{\boldsymbol{i}}\right)$ and $(z 2$, $\left.u_{i}\right)$, where $1 \leq i \leq n$. We will check the radiocondition for $(z 1, z 2),\left(z 1, v_{i}\right)$ and $\left(z 1, u_{i}\right)$.

Subcase 2.1:Consider the pair $(z 1, z 2)$. Since $f(z 1)=4 n+4, f(z 2)=4 n+7$ and $d(z 1, z 2)=$ 3.So, the radio condition becomes

$d(z 1, z 2)+|f(z 1)-f(z 2)|=3+|4 n+4-4 n-7|=6$.

Subcase 2.2: Consider the pair $\left(z 1, v_{\boldsymbol{i}}\right)$, where $z 1=v_{\boldsymbol{i}}$. As $d\left(z 1, v_{\boldsymbol{i}}\right)=1$ for $1 \leq \boldsymbol{i} \leq n$. Since $f\left(v_{\boldsymbol{i}}\right) \in\{1,5,9,15,19, \ldots, 2 n+5,2 n+9,2 n+13, \ldots, 4 n-1\}$ and $f(z 1)=4 n+4$. So, the radio condition becomes

$d\left(z 1, v_{\boldsymbol{i}}\right)+\left|\boldsymbol{f}(z 1)-\boldsymbol{f}\left(v_{\boldsymbol{i}}\right)\right| \geq 1+|4 n+4-4 n+1|, \operatorname{ord}\left(z 1, v_{\boldsymbol{i}}\right)+\left|\boldsymbol{f}(z 1)-\boldsymbol{f}\left(v_{\boldsymbol{i}}\right)\right| \geq 1+5$, or $d\left(z 1, v_{\boldsymbol{i}}\right)+$ $\left|\boldsymbol{f}\left(z_{1}\right)-\boldsymbol{f}\left(v_{\boldsymbol{i}}\right)\right| \geq 6$.

Subcase 2.3: Consider the pair $\left(\mathrm{z}_{1}, \mathrm{u}_{\mathbf{i}}\right)$, where $z_{1}=u_{\boldsymbol{i}}$. As $d\left(z_{1}, u_{\boldsymbol{i}}\right) \leq 4$ for $1 \leq \boldsymbol{i} \leq n$. Since $f\left(u_{i}\right) \in\{2,8,12,16,21,25, \ldots, 2 n+11,2 n+15, \ldots, 4 n+1\}$ and $f(z 1)=4 n+4$. So, the radio condition becomes

$d\left(z 1, u_{\boldsymbol{i}}\right)+\left|f(z 1)-f\left(u_{\boldsymbol{i}}\right)\right| \geq 4+\mid 4 n+4-4 n-11$, or $d\left(z 1, u_{\boldsymbol{i}}\right)+\left|f(z 1)-f\left(u_{\boldsymbol{i}}\right)\right| \geq 7$, or $d\left(z 1, u_{\boldsymbol{i}}\right)+$ $\left|f(z 1)-f\left(u_{i}\right)\right| \geq 6$.

Hence, the radio condition is satisfied in subcase 2.1,2.2 and 2.3. Similarly we can check the radio condition for the pairs of vertices $(\mathrm{z} 2, \mathrm{vi})$ and $(\mathrm{z} 2, \mathrm{u} \mathbf{i})$.

Case 3:Finally, consider(vi,$\left.u_{\mathbf{j}}\right)$ for $1 \leq \mathrm{i}, \mathbf{j} \leq \mathrm{n}$. As d(vi, $\left.\mathrm{u}_{\mathbf{j}}\right) \leq 5$. Wehave $\boldsymbol{f}\left(v_{\boldsymbol{i}}\right) \in\{1,5,9,15$, $19, \ldots, 2 n+5,2 n+9,2 n+13, \ldots, 4 n-1\}$ and $f\left(u_{i}\right) \in\{2,8,12,16,21,25, \ldots, 2 n+11,2 n+$ $15, \ldots, 4 n+1\}$. The possible difference of labels for each pair will satisfy $\left|\boldsymbol{f}\left(v_{\boldsymbol{i}}\right)-\boldsymbol{f}\left(u_{\boldsymbol{j}}\right)\right| \geq 1$. The radiocondition becomes

$d\left(v_{\boldsymbol{i}}, u_{\boldsymbol{j}}\right)+\left|\boldsymbol{f}\left(v_{\boldsymbol{i}}\right)-\boldsymbol{f}\left(u_{\boldsymbol{j}}\right)\right| \geq 5+1$, or $d\left(v_{\boldsymbol{i}}, u_{\boldsymbol{j}}\right)-\left|\boldsymbol{f}\left(v_{\boldsymbol{i}}\right)-\boldsymbol{f}\left(u_{\boldsymbol{j}}\right)\right| \geq 6$.

Hence, the radio condition is satisfied in this case. 
International journal on applications of graph theory in wireless ad hoc networks and sensor networks (GRAPH-HOC) Vol.3, No.4, December 2011

These three cases(for $\mathrm{n}$ is even and odd) establish the claim that $\mathbf{f}$ is a valid radio labeling of $W H_{n}$. Thus, $r n\left(W H_{n}\right) \leq \operatorname{span}(\boldsymbol{f})=4 n+7$.

Note: For $\mathrm{n}=3$, diameter of $\mathrm{WH}_{3}$ is 3 . It is easy to find that the radio number of $\mathrm{WH}_{3}$ is 12 . For $4 \leq \mathrm{n} \leq 9$, the $\mathrm{rn}\left(\mathrm{WH}_{\mathrm{n}}\right)$ cannot be found usingthe above procedure. Itseasy to see that for $3 \leq \mathrm{n}$ $\leq 9$, we have

Theorem 3.10.For $\mathrm{n} \geq 10$ the radio number of Joint Wheel graph $\left(\mathrm{WH}_{\mathbf{n}}\right)$ is

$$
r n\left(W H_{n}\right)=4 n+7 \text {. }
$$

Proof.Follows from Theorem 3.8 and Theorem 3.9.

Open problem:Investigate the $\mathrm{rn}\left(\mathrm{FW}_{n}^{\mathrm{k}}\right)$ when the copies of Wheel graphhasdifferent number of vertices.

\section{References.}

[1] G. Chartrand, D. Erwin, and P. Zhang, Graph labeling problem suggested by FM channel restrictions, Bull. Inst. Combin. Appl., 43, 43-57(2005).

[2] G. Chartrand, D. Erwin,P. Zhang, and F. Harray, Radio labelings of graphs, Bull. Inst. Combin. Appl., 33, 77-85(2001).

[3] C. Fernandaz, A. Flores, M. Tomova, and C. Wyels, The Radio Number of Gear Graphs, arXiv:0809. 2623, September 15, (2008).

[4] J. A. Gallian, A dynamic survey of graph labeling, Electronic J. of Combinatorics, DS NO. 06, 16(2009).

[5] W. K. Hale, Frequency assignment: theory and applications, Proc. IEEE, 68(1980), 1947-1514.

[6] R. Khennoufa and O. Togni, The Radio Antipodal and Radio Numbers of the Hypercube, accepted in 2008 publication in ArsCombinatoria.

[7] D. Liu, Multi-level distance labelings for tree, Discrete Mathematics, Vol.308(7), 11531164, 2007.

[8] D. Liu and X. Zhu, Multi-level distance labelings for paths and cycles, SIAM J. Discrete Math., Vol.19(3), 610-621, 2005.

[9] M. T. Rahim, I. Tomescu, OnMulti-level distance labelings of Helm Graphs, accepted for publication in ArsCombinatoria.

[10] M. M. Rivera, M. Tomova, C. Wyels, and A. Yeager, The Radio Number of Cn Cn,resubmitted to ArsCombinatoria, 2009. 